\title{
Numerical Simulations of the Flow and Sediment Transport Regimes Surrounding a Short Cylinder
}

\author{
Kimberly A. Hatton, Diane L. Foster, Peter Traykovski, and Heather D. Smith
}

\begin{abstract}
The 3-D flow field and bed stress surrounding a short cylinder in response to combined wave and mean-flow forcing events is examined. Model simulations are performed with a 3-D nonhydrostatic computational fluid dynamics model, FLOW-3D. The model is forced with a range of characteristic tidal and wave velocities as observed in 12-15 $\mathrm{m}$ of water at the Martha's Vineyard Coastal Observatory (MVCO, Edgartown, MA). The 2.4-m-long and 0.5-m diameter cylinder is buried $10 \%$ of the diameter on a flat, fixed bed. Regions of incipient motion are identified through local estimates of the Shields parameter exceeding the critical value. Potential areas of sediment deposition are identified with local estimates of the Rouse parameter exceeding ten. The model predictions of sediment response are in general in agreement with field observations of seabed morphology obtained over a one-week period during the 2003-2004 MVCO mine burial experiment. Both observations and simulations show potential transport occurring at the ends of the mine in wave-dominated events. Mean flows greater than $10 \mathrm{~cm} / \mathrm{s}$ lead to the formation of larger scour pits upstream of the cylinder. Deposition in both cases tends to occur along the sides, near the center of mass of the mine. However, the fixed-bed assumption prohibits the prediction of full perimeter scour as is observed in nature. Predicted scour and burial regimes for a range of wave and mean-flow combinations are established.
\end{abstract}

Index Terms-Mine, scour, sediment transport.

\section{INTRODUCTION}

$\mathbf{T}$ HE scouring of an erodible bed surrounding a submarine object requires an understanding of the deformation of the flow field around the object as well as the response of the underlying sediment. Historical scour investigations of objects in aquatic environments have largely been focused on vertical piles or horizontal pipelines subjected to steady flow [1]. In the case of vertical piles [2], sediment is eroded around the pile circumference, while in the case of horizontal pipelines [3], [4], sediment is eroded from under the pipeline. The eroded sediment that often deposits in the far wake as the flow reattaches can

Manuscript received June 30, 2005; revised September 8, 2005; accepted October 13,2005 . This work was supported in part by the U.S. Office of Naval Research under the mine burial project N00014-00-1-0570. The work of K. A. Hatton was supported by the National Science Foundation Graduate Research Fellowship.

Guest Editor: R. H. Wilkens.

K. A. Hatton was with the Environmental Engineering and Geodetic Science, Ohio State University, Columbus, OH 43210-1275 USA. She is now with the Malcolm Pirnie Inc., Columbus, OH 43240-2020 USA.

D. L. Foster and H. D. Smith are with the Environmental Engineering and Geodetic Science, Ohio State University, Columbus, OH 43210-1275 USA (e-mail: foster.316@osu.edu).

P. Traykovski is with the Applied Ocean Physics and Engineering Department, Woods Hole Oceanographic Institution, Woods Hole, MA 02543 USA (e-mail: ptraykovski@whoi.edu).

Digital Object Identifier 10.1109/JOE.2007.890986 eventually compromise the structure support. The evolution of the bed surrounding these objects is dependent on the object geometry, the wave and mean-flow forcing, and the sediment characteristics. Small variations in each of these parameters can lead to vastly different scour and burial regimes.

Our ability to model scour and burial around submerged obstacles depends on how well the flow around the obstacle and the individual sediment transport mechanisms can be resolved. Even in steady forcing environments, the flow fields around 3-D objects are complex with temporally varying 3-D flow often characterized by an upstream horseshoe vortex, streamline contraction around the object, and vortex shedding in the wake. For vertical piles, the initiation of scour is generally governed by the horseshoe vortex and the contraction of streamlines [1]. Pipeline scour is initiated by a horizontal pressure gradient across the pipeline which induces a groundwater flow that ejects the supporting sediment from beneath the object [5]. In wave environments, the scour surrounding 2-D objects (i.e., vertical piles and pipelines) scales with the orbital excursion of the waves relative to the object diameter. It is commonly parameterized with the Keulegan-Carpenter number (KC) given by

$$
\mathrm{KC}=\frac{U_{\text {wave }} T}{D}
$$

where $U_{\text {wave }}$ is the amplitude of the maximum value of the undisturbed wave velocity outside the wave boundary layer, $T$ is the wave period, and $D$ is the object diameter [6], [1], [7]. For small bodies $(\mathrm{KC}<O(100))$, the scour is dependent on vortex shedding in the wake of the object.

Recent laboratory and numerical investigations have considered the effects of introducing surface-mounted, 3-D objects to flow fields. Several geometries have been examined including [8] pyramids [9], cubes [10], [11], [8], spheres [12], hemispheres [13], and short cylinders [14]. The deformations of the flow field around and over the object ends reduces the horizontal pressure gradient applied across the object diameter and may reduce or eliminate the piping present on 2-D pipelines. The flow deformation over the object also reduces the strength of the horseshoe vortex as is present with 2-D vertical piles. A limited number of laboratory investigations [15], [13] have considered the flow field and scour around 3-D objects in wave and mean-flow environments. The scour around surface-mounted spheres in wave environments has been shown to have smaller volumes than in comparable mean-flow environments [12]. Truelsen $e$ al. [12] also showed that the scour in wave environments is a function of both the bed stress and the $\mathrm{KC}$ number. However, in the mean-flow environment, the scour is purely a function of the bed stress.

The geometry of short, horizontal cylinders (i.e., mines) creates a new set of hydrodynamic conditions resulting from the 


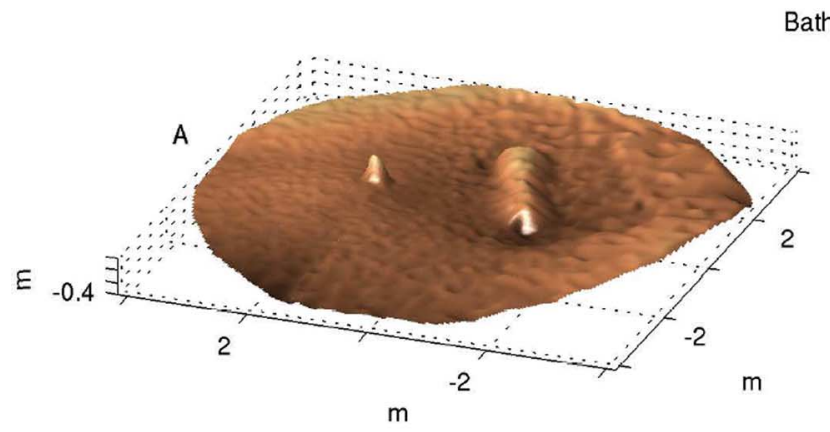

Bathymetry
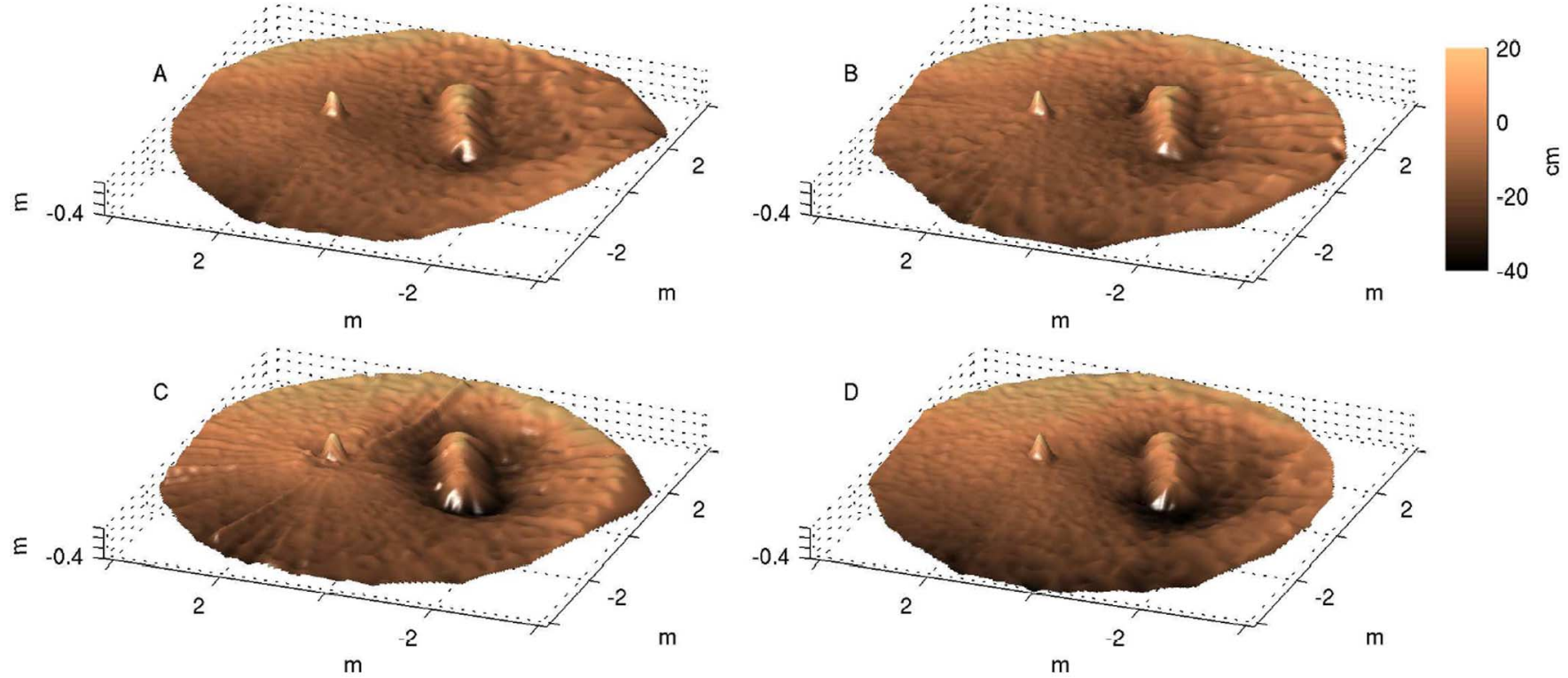

Velocity

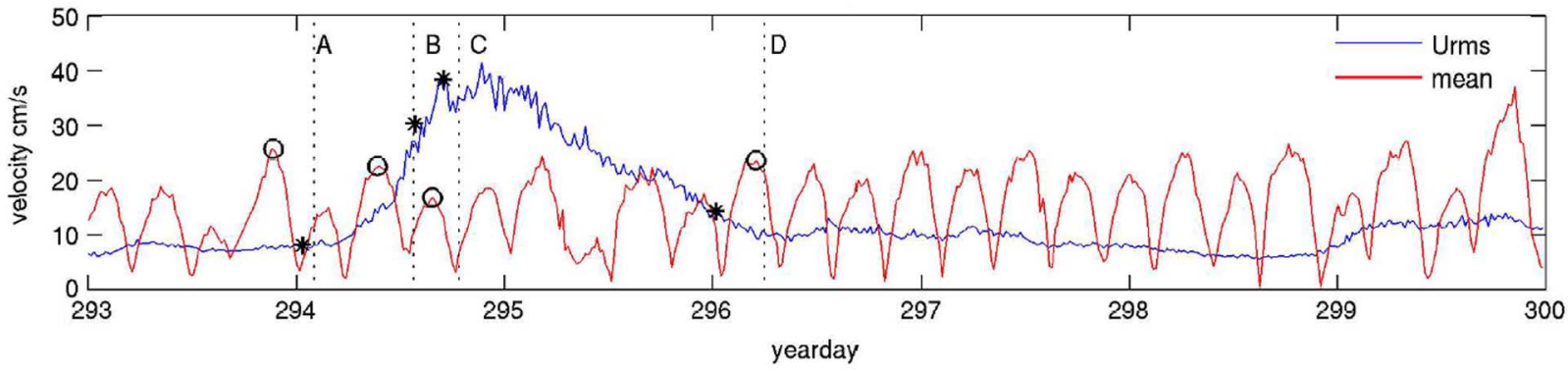

Fig. 1. Acoustic images obtained during the MVCO experiment show the seabed geometry surrounding a single cylinder (a) before, (b) during, (c) near the peak, and (d) following the storm. The cone shape seen in the upper left side of (a)-(d) is the instrument mount. A time series of the 3-h mean $U_{\text {mean }}$ and root-meansquared (rms) horizontal velocities $\left(U_{\text {wave }} / \sqrt{2}\right)$ are given in the lower panel. The vertical lines correspond to morphology images (a)-(d) above. Peak mean and rms velocities in the $6 \mathrm{~h}$ before each of the morphology images (a)-(d) are identified with o and $*$, respectively.

3-D flow field and the ability of the cylinder to roll, shift, and rotate on the bed. Lab investigations exposing a submerged short cylinder to waves showed that the 3-D scour pattern is correlated to both the Shields parameter and vortex shedding [15]. Field observations of cylindrical mines in coastal environments, where wave and tidal velocities are often perpendicular, have shown that the cylinder generally rotates until the longitudinal axis is parallel to mean flows and perpendicular to the direction of wave propagation [16]. Previous studies have indicated that cylindrical mines scour by a repeated sequence of the mine scouring, rolling into the scour pit, and scouring again until buried. Over a single storm event, the bed shows significant variation in scour and burial regimes. Complete perimeter scour surrounding the mine occurs in high forcing conditions and partial burial occurs in low forcing conditions [16].

The objective of this investigation is to examine the initiation of scour and deposition surrounding a short cylindrical object resting on a bed using a 3-D computational fluid dynamics model. Predictions of the initiation of scour and deposition surrounding the object are made for a variety of wave and mean-flow climates consistent with two full-scale field experiments. Consistent with available field observations, the cylinder is oriented parallel to the mean flows and perpendicular to wave propagation. These simulations are evaluated with field observations obtained before, during, and following an observed storm event. Finally, regimes of scour and deposition initiation are identified over a range of wave and mean-flow conditions.

\section{OBSERVATIONS}

The objective of the 2003-2004 collaborative Martha's Vineyard Coastal Observatory (MVCO, Edgartown, MA) mine burial experiment was to observe the near- and far-field wave and sediment climatology surrounding inert cylindrical mines placed on a sediment bed. The cylindrical objects were placed in intermediate water depths of 12-15 m [17]. In the near-field, the free-stream velocity field, cylinder orientation, and seabed geometry surrounding a short, cylindrical, mine-like object were observed. Vertical profiles of velocity were measured at $50-\mathrm{cm}$ range bins with an upward looking acoustic Doppler profiler (ADP) located $20 \mathrm{~m}$ from the object. Observations of seabed geometry and backscatter intensity were obtained with a two-axis rotary sonar with a set frequency of $975 \mathrm{kHz}$. The instrument resolved the bed morphology and backscatter intensity over a 4-m radius surrounding the object, with a spatial resolution of approximately $10 \mathrm{~cm}$ in the horizontal and 
approximately $5 \mathrm{~cm}$ in the vertical. The longitudinal axis of the cylinder was oriented $88^{\circ}$ relative to the north.

During the two-month experiment, a single storm event with significant waveheights of up to $3 \mathrm{~m}$, wave periods ranging from 4 to $8 \mathrm{~s}$, and orbital wave velocities $U_{\text {wave }}$ up to $50 \mathrm{~cm} / \mathrm{s}$ in the north-south direction, occurred (Fig. 1). The orientation of tidal flows relative to the north $\alpha_{\text {mean }}$ during the observations of interest was generally $100^{\circ}$, while $\alpha_{\text {wave }}$ was $210^{\circ}$. This two-day storm event resulted in large evolutions of the local seabed geometry surrounding the cylinder.

\section{MODEL}

The 3-D flow simulations are performed with a commercial nonhydrostatic finite-difference model, FLOW-3D. This model has previously been used to resolve the flow and scour around bridge piers [18] and the flow around a submarine pipeline [19]. The model resolves fluid-fluid and fluid-air interfaces with a nonboundary fitted rectangular grid and a volume of fluid (VOF) approach which resolves the grid cells into separate fractionalfluid components containing the fraction of water and fraction of solid in the cell. Similarly, a fractional area-volume obstacle representation (FAVOR) approach is used to parametrize the flow within cells which contain fluid-obstacle boundaries.

The model solves the 3-D Reynolds averaged Navier-Stokes (RANS) equations for incompressible flow simultaneously with the continuity equation given by

$$
\frac{\partial}{\partial x_{i}} u_{i} A_{i}=0
$$

The RANS equations are given as

$$
\frac{\partial u_{i}}{\partial t}+\frac{1}{V_{f}}\left[u_{j} A_{j} \frac{\partial u_{i}}{\partial x_{j}}\right]=-\frac{1}{\rho} \frac{\partial P}{\partial x_{i}}+G_{i}+f_{i}
$$

where

$$
\begin{aligned}
f_{i} & =\frac{1}{V_{f}}\left[\frac{\tau_{b, i}}{\rho}-\frac{\partial}{\partial x_{j}}\left(A_{j} S_{i j}\right)\right] \\
S_{i j} & =-\left(\nu+\nu_{t}\right)\left[\frac{\partial u_{i}}{\partial x_{j}}+\frac{\partial u_{j}}{\partial x_{i}}\right]
\end{aligned}
$$

where $u_{i}$ is the mean velocity, $P$ is the pressure, $A_{i}$ is the fractional open area open to flow in the $i$ direction, $V_{f}$ is the fractional volume open to flow, $G_{i}$ represents the body accelerations, $f_{i}$ represents the viscous accelerations, $S_{i j}$ is the strain rate tensor, $\tau_{b, i}$ is the wall shear stress, $\rho$ is the density of water, $\nu$ is the kinematic viscosity, and $\nu_{t}$ is the kinematic eddy viscosity.

In these simulations, the equations of motion are closed with the standard $k-\epsilon$ closure scheme given by

$$
\nu_{T}=\frac{C_{\mu} k^{2}}{\epsilon}
$$

where $k$ is the turbulent kinetic energy, $C_{\mu}$ is a closure coefficient, and $\epsilon$ is the dissipation rate as given in [20]. Comparisons of $k-\epsilon$, renormalization group (RNG), and large eddy simulation (LES) closure schemes with laboratory observations of a 2-D cylinder lying on a flat bed and over a scoured bed found that the mean-velocity predictions for each of the closure

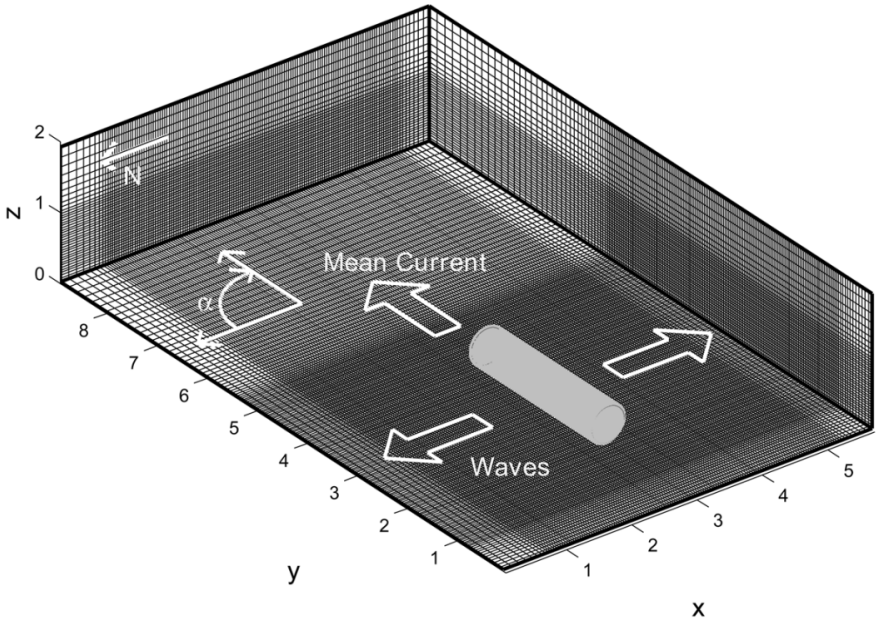

Fig. 2. Grid used to resolve the flow around the cylinder. All units are in meters. The cylinder is buried by $10 \%$ of its diameter (i.e., $5 \mathrm{~cm}$ ), which results in a $0.3 \mathrm{~m} \times 2.4-\mathrm{m}$ bed surface area occupied by the cylinder.

schemes were within $4 \%$ of the data [19]. The $k-\epsilon$ closure accurately predicted the wake reattachment point of the cylinder placed on a flat bed. Predictions of the Strouhal number with the $k-\epsilon$ closure scheme were consistent with the observations; however, the amplitude of the vortex shedding was smaller than the LES predictions and dependent on the grid resolution.

In these calculations, a fixed horizontal cylinder, $2.4 \mathrm{~m}$ in length with a diameter of $0.5 \mathrm{~m}$, is lying on a flat, fixed bed. To be consistent with the initial sonar observations of the cylinder position, the burial depth of the cylinder in the simulations was chosen as $10 \%$ of the diameter. This resulted in a $0.3-\mathrm{m}$-wide and 2.4-m-long section of bed surface area occupied by the cylinder. The domain is resolved with a rectangular grid with $0.035 \mathrm{~m} \times 0.035 \mathrm{~m} \times 0.035-\mathrm{m}$ cells in the region immediately surrounding the cylinder which is linearly stretched to $0.1 \mathrm{~m} \times 0.1 \mathrm{~m} \times 0.1 \mathrm{~m}$ at the boundaries (Fig. 2). A domain size of $6 \mathrm{~m} \times 9 \mathrm{~m} \times 2 \mathrm{~m}$ allowed for the upstream development of the bottom boundary layer and the downstream evolution of the wake. This resulted in 157, 215, and 38 grid cells in the domain in the $x-, y$-, and $z$-directions, respectively. The equilibrium time for each simulation was determined as the time required for the fluid at the beginning of the domain to reach the downstream boundary (i.e., model simulation time was 112 and $49 \mathrm{~s}$ for mean-flow velocities of 10 and $25 \mathrm{~cm} / \mathrm{s}$, respectively). The equilibrium time for simulations with $0 \mathrm{~cm} / \mathrm{s}$ mean-flow velocity was three complete wave periods. Time step sizes for the simulations are calculated by the model to ensure numerical stability. For the simulations, the direction of wave propagation and mean flow is assumed to be $0^{\circ}$ and $90^{\circ}$ relative to north, respectively. Consequently, the north and south boundaries were forced with time-dependent free-stream wave velocities. Consistent with the MVCO observations (see Table I for a summary of the observations), these velocities vary from 0 to $50 \mathrm{~cm} / \mathrm{s}$, with a wave period of $7 \mathrm{~s}$. The west boundary was forced with the mean-flow velocities varying from 0 to $25 \mathrm{~cm} / \mathrm{s}$, and the east boundary was defined with a continuative outflow condition (see Table II for a summary of the simulations). A no-slip condition was assumed at the bottom boundary, and a Nikuradse bed roughness $\left(k_{s}=2.5 d_{50}\right)$ equivalent to the fine grain $\left(d_{50}=\right.$ 
TABLE I

OBSERVEd FreE-STREAM Flow CONDITIONS DURING THE STORM

\begin{tabular}{|c||c||c||c||c||c|}
\hline Observation & $\begin{array}{c}U_{\text {wave }} \\
(\mathrm{cm} / \mathrm{s})\end{array}$ & $\begin{array}{c}U_{\text {mean }} \\
(\mathrm{cm} / \mathrm{s})\end{array}$ & $\begin{array}{c}T \\
(\mathrm{~s})\end{array}$ & $\begin{array}{c}K C \\
=\frac{U_{\text {wave } T}}{D}\end{array}$ & $\begin{array}{c}R_{e_{\text {mean }}} \\
=\frac{U_{\text {mean }} D}{\nu}\end{array}$ \\
\hline Before Event & 8 & 26 & 4 & 0.6 & $13 \times 10^{4}$ \\
Initiation of Perimeter Scour & 30 & 23 & 6 & 3.6 & $11.5 \times 10^{4}$ \\
Complete Perimeter Scour & 39 & 17 & 6.5 & 5.1 & $8.5 \times 10^{4}$ \\
Following Event & 14 & 24 & 8 & 2.2 & $12.0 \times 10^{4}$ \\
\hline
\end{tabular}

TABLE II

ForCING CONDITIONS FOR MODEL SIMULATIONS

\begin{tabular}{|c||c||c||c||c||c|}
\hline Simulation & $\begin{array}{c}U_{\text {wave }} \\
(\mathrm{cm} / \mathrm{s})\end{array}$ & $\begin{array}{c}U_{\text {mean }} \\
(\mathrm{cm} / \mathrm{s})\end{array}$ & $\begin{array}{c}T \\
(\mathrm{~s})\end{array}$ & $\begin{array}{c}K C \\
=\frac{U_{\text {wave }} T}{D}\end{array}$ & $\begin{array}{c}R_{e_{\text {mean }}} \\
=\frac{U_{\text {mean }} D}{\nu}\end{array}$ \\
\hline $1 \mathrm{a}$ & 0 & 0 & 7 & 0 & 0 \\
$\mathrm{~b}$ & 0 & 10 & 7 & 0 & $5.0 \times 10^{4}$ \\
$\mathrm{c}$ & 0 & 25 & 7 & 0 & $12.5 \times 10^{4}$ \\
$2 \mathrm{a}$ & 10 & 0 & 7 & 1.4 & 0 \\
$\mathrm{~b}$ & 10 & 10 & 7 & 1.4 & $5.0 \times 10^{4}$ \\
$\mathrm{c}$ & 10 & 25 & 7 & 1.4 & $12.5 \times 10^{4}$ \\
$3 \mathrm{a}$ & 25 & 0 & 7 & 3.5 & 0 \\
$\mathrm{~b}$ & 25 & 10 & 7 & 3.5 & $5.0 \times 10^{4}$ \\
$\mathrm{c}$ & 25 & 25 & 7 & 3.5 & $12.5 \times 10^{4}$ \\
$4 \mathrm{a}$ & 50 & 0 & 7 & 7 & 0 \\
$\mathrm{~b}$ & 50 & 10 & 7 & 7 & $5.0 \times 10^{4}$ \\
$\mathrm{c}$ & 50 & 25 & 7 & 7 & $12.5 \times 10^{4}$ \\
\hline
\end{tabular}

$0.15 \mathrm{~mm}$ ) sands typical of the MVCO site was assumed. A symmetry condition was assumed at the top of the domain.

\section{RESULTS}

Model simulations are performed for the range of wave and mean forcing conditions specified in Table II. Locations of incipient motion are assumed when the maximum value of the magnitude of the Shields parameter $\left(|\theta(x, y, t)|_{\max }\right)$ over a wave period exceeds the critical value $\left(\theta_{\text {crit }}=0.06\right)$. The magnitude of the Shields parameter is given by

$$
\theta(x, y, t)=\sqrt{\theta_{x}^{2}(x, y, t)+\theta_{y}^{2}(x, y, t)} .
$$

The instantaneous components of the Shields parameter are defined with

$$
\theta_{i}(x, y, t)=\frac{u_{* i}^{2}(x, y, t)}{(s-1) g d_{50}}
$$

where $s$ is the specific gravity $(=2.65)$ and $d_{50}$ is the grain size $(=0.15 \mathrm{~mm})$. The shear velocity $u_{* i}(x, y, t)$ is calculated with a two-point linear interpolation at the bed given by

$$
u_{* i}(x, y, t)=\frac{\kappa u_{i}\left(x, y, z_{1}, t\right)}{\ln \left(\frac{z_{1}}{z_{o}}\right)}
$$

where $\kappa$ is the von Karman constant, $u_{i}\left(x, y, z_{1}, t\right)$ is the velocity in the $i$ direction at $z=z_{1}(=1.73 \mathrm{~cm}$ off the bed $)$, and $z_{0}=2.5 d_{50} / 30$ [21].

Here, the maximum Shields parameter is assumed to occur at the peak wave velocity. The resolution of the near-bed domain $\left(\Delta z_{\text {bed }}=1.1 \mathrm{~cm}\right)$ prohibits the characterization of the flow through the wave bottom boundary layer. In the following simulation, the wave bottom boundary layer thickness is always less than $3.5 \mathrm{~cm}$. This quasi-steady approach will result in the bed stress being in phase with the free-stream velocity. The tendency of sediment to deposit is characterized with values of the nondimensional Rouse parameter, which represents the balance between the settling velocity and a measure of the turbulent fluctuations required to maintain sediment suspension and is given by

$$
R o=\frac{w_{s}}{\kappa u_{*}}
$$

where $w_{s}$ is the settling velocity as defined by

$$
w_{s}^{2}=\frac{\frac{4}{3}(s-1) g d_{s}}{c_{D}}
$$

where $s$ is the relative density of the sediment, $g$ is gravity, $d_{s}$ is the grain sieve diameter, and $c_{D}$ is given by

$$
c_{D}=1.4+36 / R_{e p}
$$

where $R_{e p}$ is the grain Reynolds number given as

$$
R_{e p}=\frac{w_{s} d_{50}}{\nu}
$$

where $\nu$ is the kinematic viscosity. Sediment is assumed to deposit at a location when the minimum Rouse parameter over the wave cycle exceeds ten [21]. The minimum Rouse parameter occurs at maximum shear stress over a wave period for each cell and is, therefore, the most restrictive estimate for sediment deposition.

The model is evaluated with the sonar observations shown in Fig. 1 and described in Table I. In each of the four cases, we compare the model simulations with the forcing conditions most consistent with the observations. Direct comparison with the model is not possible because the model simulations all assume a flat, immobile bed with a cylinder burial of $10 \%$. Instead, we evaluate the predicted scour and depositional susceptibility with the evolution of the observations in response to the hydrodynamic forcing.

Before the storm on October 21, 2003 at 02:00:00 A.M., flow conditions $\left(U_{\text {wave }}=8 \mathrm{~cm} / \mathrm{s}\right.$ and $\left.U_{\text {mean }}=26 \mathrm{~cm} / \mathrm{s}\right)$ are consistent with the forcing conditions of simulation $2 \mathrm{c}$ ( $U_{\text {wave }}=$ $10 \mathrm{~cm} / \mathrm{s}$ and $U_{\text {mean }}=25 \mathrm{~cm} / \mathrm{s}$ ). There exists two areas exceeding the critical limit for incipient motion, each approximately 1.5 cylinder diameters in width, at the end of the cylinder upstream of the mean flow [Fig. 3(a)]. Within these areas, the maximum Shields parameter reaches 0.2. Smaller areas of incipient motion, approximately 0.5 cylinder diameters wide, develop at the opposite end of the cylinder. Deposition for this simulation, as predicted by the Rouse parameter, is limited to the area immediately next to the cylinder [Fig. 3(b)]. The observations [Fig. 3(c)] 


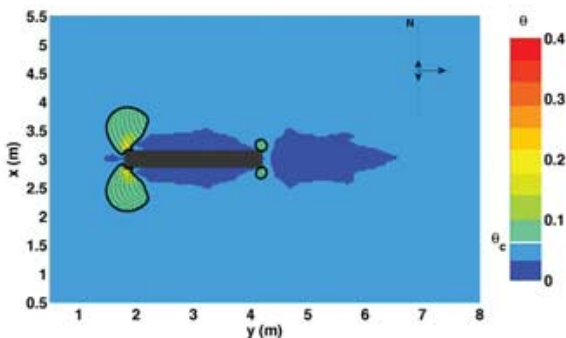

(a)

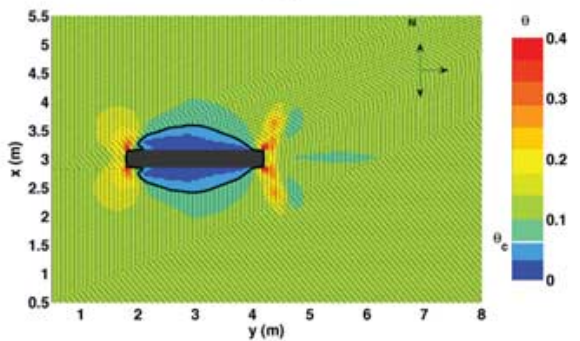

(d)

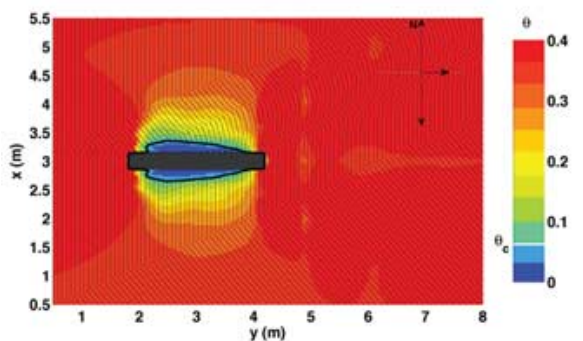

(g)

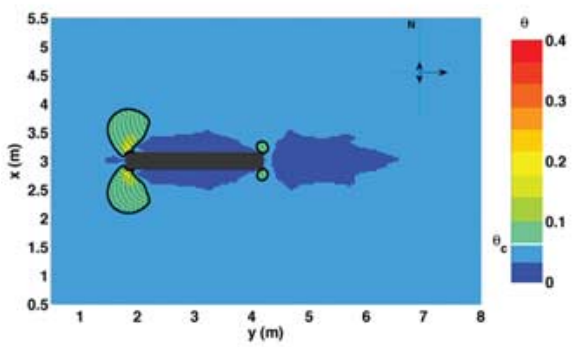

(j)

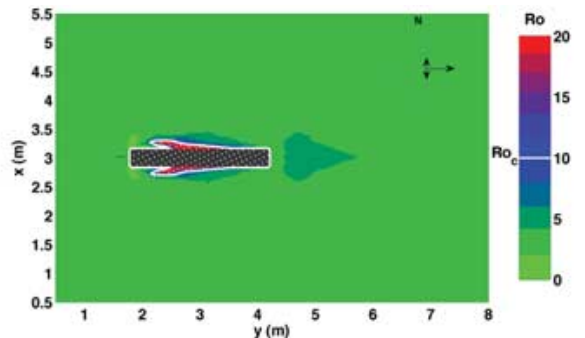

(b)

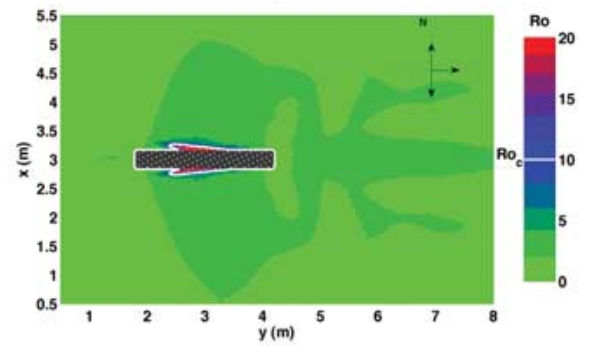

(e)

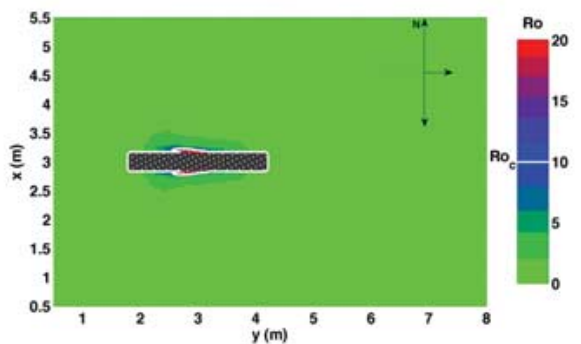

(h)

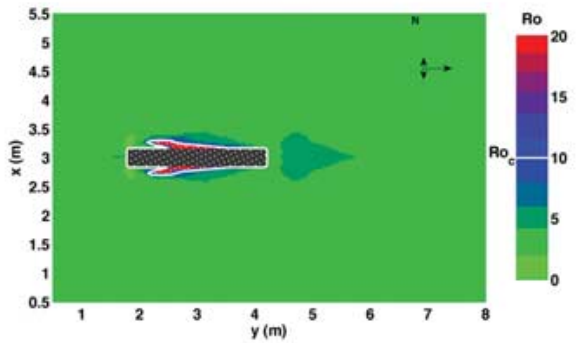

(k)

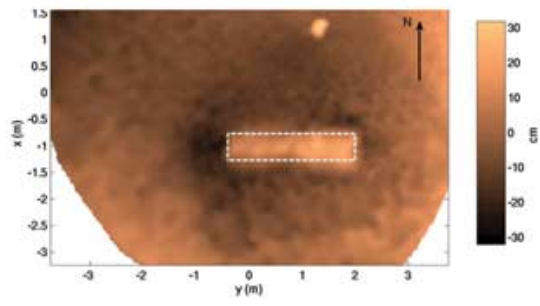

(c)

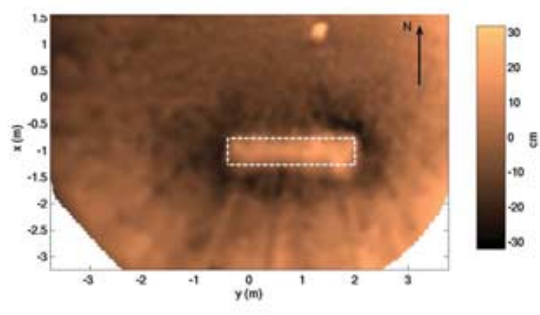

(f)

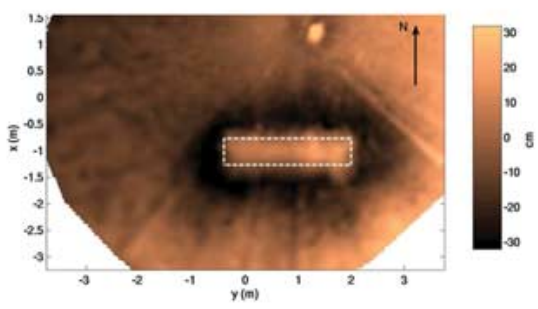

(i)

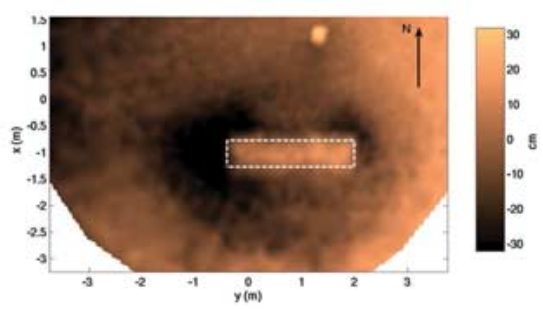

(1)

Fig. 3. (a), (d), (g), and (j) Predicted Shields parameter. Scour is predicted to occur in the hatched areas. Arrows in the upper right-hand corner show the direction of wave propagation and mean flow for the simulation. The bed surface area occupied by the cylinder is shown with the gray rectangle. (b), (e), (h), and (k) Predicted Rouse parameter. Deposition is predicted to occur in the hatched areas. (c), (f), (i), and (l) Observed seabed geometry surrounding the cylinder. The cylinder (dashed white rectangle) is located at the center of the observed area, while the small circle above the cylinder represents the instrument pole.

show a bed depression indicative of ongoing scour occurring at the west end of the cylinder to a depth of $23 \mathrm{~cm}$ below the far-field bed elevation. A small area of scour also occurs at the northeast end of the cylinder, approximately 0.5 cylinder diameters wide, and is consistent with the predictions for simulation $2 c$. The observations are generally not inconsistent with the simulation. However, the predicted region of scour at the west end is larger than observed and the small scour area at the southeast end of the cylinder is not present. This deviation may result from the forced wave velocity being slightly larger than the observed velocity and also the assumed $90^{\circ}$ approach of the mean flow.

At the initiation of the storm on October 21, 2003 at 02:00:00 P.M., the flow conditions $\left(U_{\text {wave }}=30 \mathrm{~cm} / \mathrm{s}\right.$ and $U_{\text {mean }}=23 \mathrm{~cm} / \mathrm{s}$ ) are consistent with the forcing conditions of simulation $3 \mathrm{c}\left(U_{\text {wave }}=25 \mathrm{~cm} / \mathrm{s}\right.$ and $\left.U_{\text {mean }}=25 \mathrm{~cm} / \mathrm{s}\right)$. The critical limit for incipient motion is exceeded at both ends of the cylinder and along the cylinder to approximately $15 \%$ of the length [Fig. 3(d)]. Deposition is limited to areas immediately alongside the longitudinal axis of the cylinder [Fig. 3(e)]. The observations [Fig. 3(f)] show the onset of scour surrounding the entire perimeter of the cylinder. The scour depressions extend along the longitudinal axis, $30 \%$ of the length of the cylinder, which is not predicted by the model. Consistent with the simulations, the observations show relatively small amounts of deposition during this section of the storm.

Near the peak of the storm, on October 21, 2003 at 07:00:00 P.M., the flow conditions ( $U_{\text {wave }}=39 \mathrm{~cm} / \mathrm{s}$ and $U_{\text {mean }}=17 \mathrm{~cm} / \mathrm{s}$ ) are consistent with the forcing conditions of simulation $4 \mathrm{c}\left(U_{\text {wave }}=\right.$ $50 \mathrm{~cm} / \mathrm{s}$ and $\left.U_{\text {mean }}=25 \mathrm{~cm} / \mathrm{s}\right)$. The predicted Shields parameter exceeds the critical limit for incipient motion over the en- 

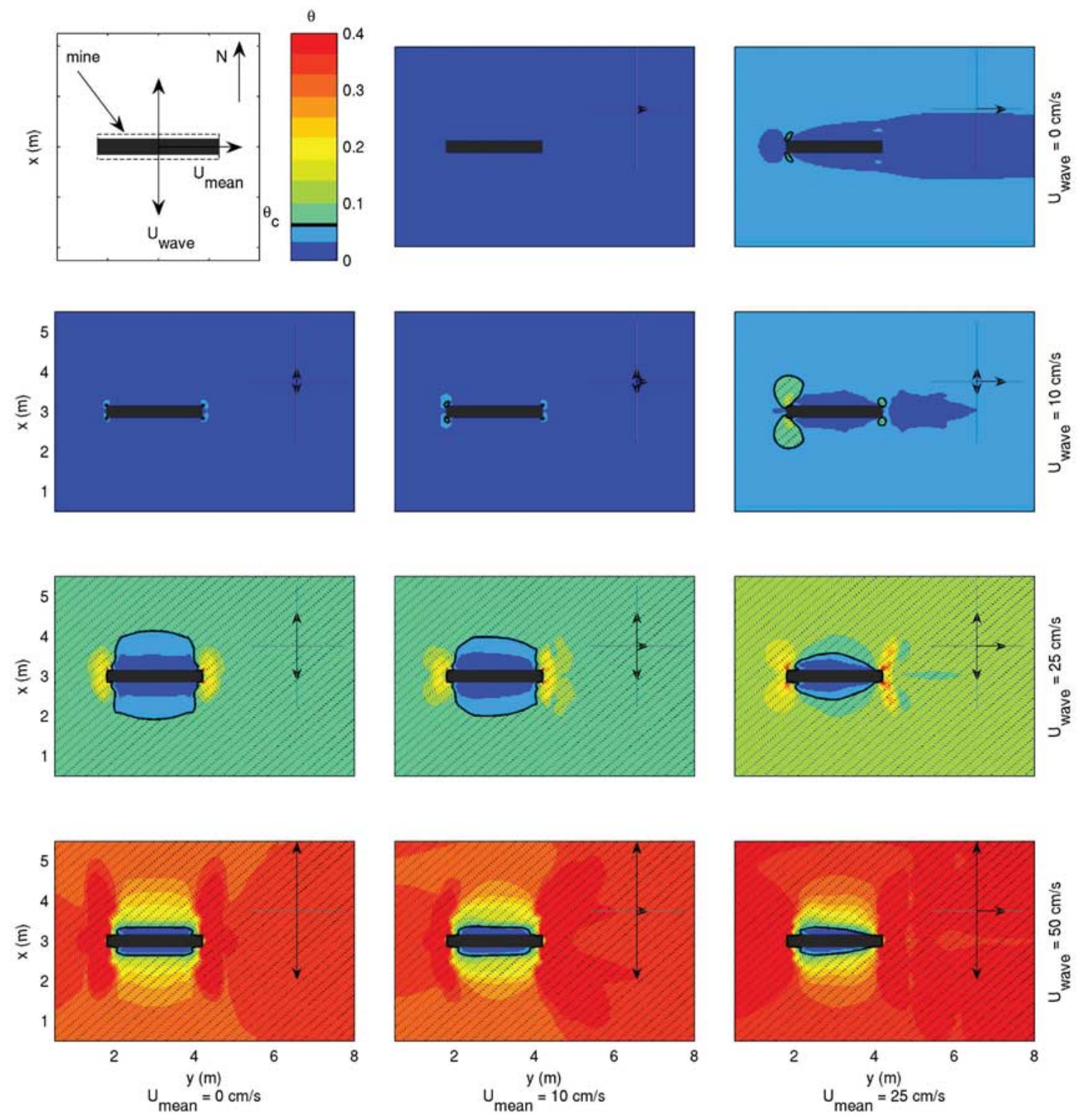

Fig. 4. Color contours of the maximum value of the Shields parameter $\theta=\left|\theta_{\max }\right|$ for wave velocities ranging from 0 (uppermost panels), 10 (upper middle panels), 25 (lower middle panels), and $50 \mathrm{~cm} / \mathrm{s}$ (lower panels) and mean-flow velocities ranging from 0 (left panels), 10 (middle panels), and $25 \mathrm{~cm} / \mathrm{s}$ (right panels). Hatched areas indicate locations where the Shields parameter exceeds the critical value for incipient motion $\left(\theta_{\text {crit }}=0.06\right)$. The gray rectangle represents the bed surface area occupied by the cylinder.

tire domain with the exception of a small, two-cylinder diameter section along the longitudinal axis of the cylinder [Fig. 3(g)]. The low values of the Rouse parameter throughout the domain suggest no additional deposition beyond the area of the cylinder which is buried [Fig. 3(h)]. The observations [Fig. 3(i)] show the scour pits previously observed have propagated along the length of the mine, leading to complete perimeter scour reaching depths of $40 \mathrm{~cm}$ below the far-field bed elevation. The fixed-bed assumption in the simulations does not resolve existing scour holes present in the field and consequently fails to predict the observed high-stress region along the cylinder perimeter. However, the model does predict the entire bed to be in motion. Mobile bed simulations of the flow around a 2-D cylinder suggest that the model may predict the perimeter scour if the observed initial bed morphology was specified [22].
Following the storm, on October 23, 2003 at 06:00:00 A.M., the flow conditions ( $U_{\text {wave }}=14 \mathrm{~cm} / \mathrm{s}$ and $U_{\text {mean }}=24 \mathrm{~cm} / \mathrm{s}$ ) are consistent with the forcing conditions of simulation $2 \mathrm{c}\left(U_{\text {wave }}=\right.$ $14 \mathrm{~cm} / \mathrm{s}$ and $U_{\text {mean }}=24 \mathrm{~cm} / \mathrm{s}$ ). The predicted Shields [Fig. 3(j)] and Rouse parameters [Fig. 3(k)] are the same as those preceding the storm. The observations [Fig. 3(1)] show a scour regime similar to that before the storm; however, the scour holes are deeper and wider. Backscatter intensity observations show that the scoured perimeter region fills with very fine-grained sediment following the storm [17]. A potential explanation for the deeper, wider scour holes is the very fine-grained sediment that scours more easily than the sand, exposing the areas previously scoured. Additionally, the wave velocities and average mean flows are slightly higher than those preceding the storm. The predicted areas of incipient motion exceeding the critical value are consistent with the observations, with the exception of 

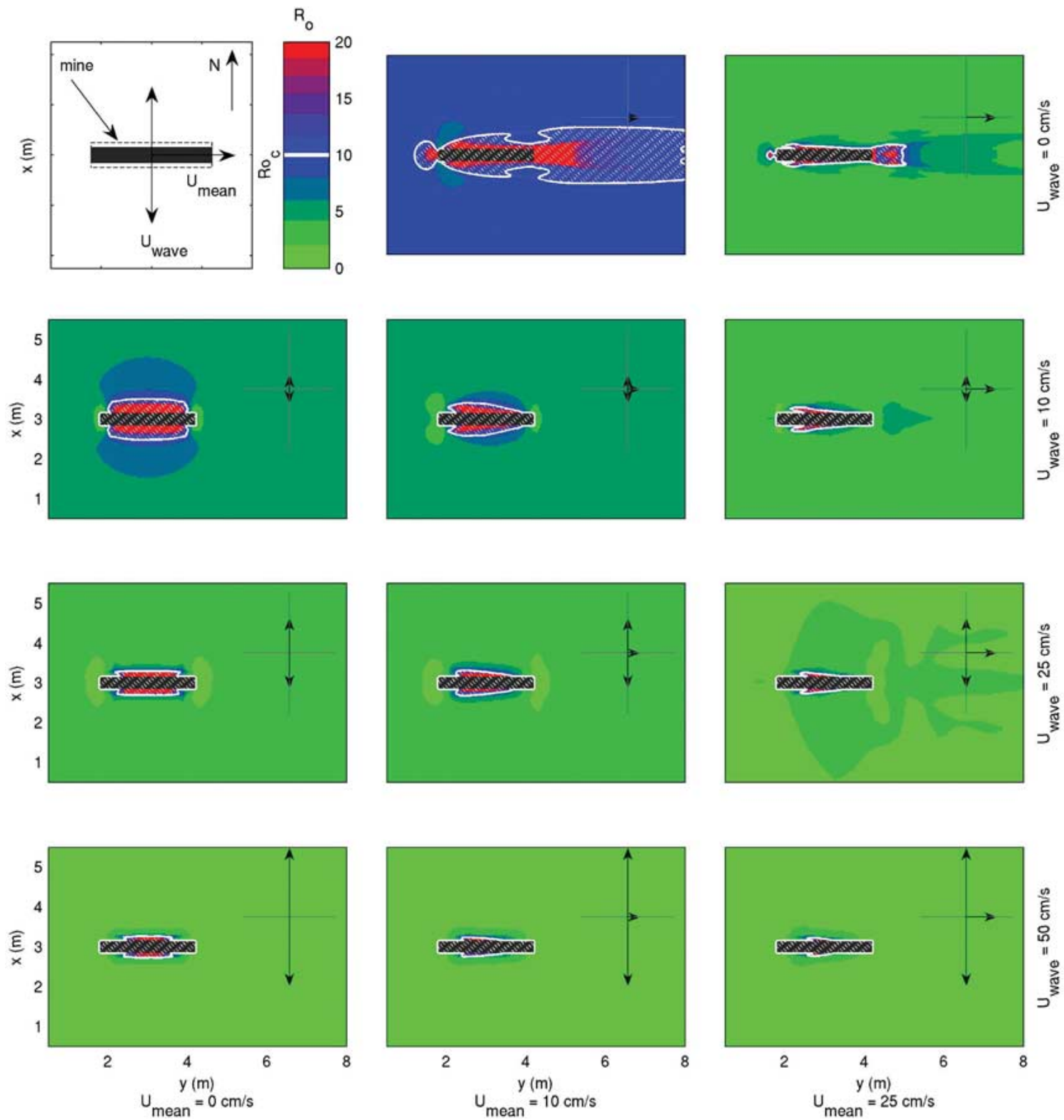

Fig. 5. Color contours of the minimum value of the Rouse parameter $R o$ for wave velocities ranging from 0 (uppermost panels), 10 (upper middle panels), 25 (lower middle panels), and $50 \mathrm{~cm} / \mathrm{s}$ (lower panels) and mean-flow velocities ranging from 0 (left panels), 10 (middle panels), and $25 \mathrm{~cm} / \mathrm{s}$ (right panels). Hatched areas indicate locations where the Rouse parameter exceeds the critical value for deposition $(R o=10)$. The gray rectangle represents the bed surface area occupied by the cylinder.

the observed scour pits at the east end of the cylinder which are larger than the simulated scour pits. Both the observations and model predictions show deposition occurring along both sides of the cylinder.

The scour and depositional regimes for the entire range of simulated wave and mean-flow velocities are given in Figs. 4 and 5 , respectively. These results indicate that regions of potential scour, as inferred by incipient motion, are most strongly correlated to wave velocities oriented perpendicular to the cylinder axis. Not surprisingly, the near-field flow response is relatively insensitive to the drag introduced by the mean flow moving parallel to the longitudinal axis of the cylinder. When the wave velocity reaches $25 \mathrm{~cm} / \mathrm{s}$, incipient motion occurs over the entire domain, although the highest scour remains at the ends of the cylinder. Increasing the wave velocity beyond $25 \mathrm{~cm} / \mathrm{s} \mathrm{de}-$ creases deposition along the cylinder and eliminates the deposition of sediment in the mean-flow wake of the cylinder. Increasing the mean flow in the simulations increases the bed stress magnitude at the west end of the cylinder in addition to forcing the sediment initiation at the east end of the cylinder downstream. Increasing the mean flow also translates the depositional areas (Fig. 5) along the length of the cylinder to taper towards the east end of the cylinder. The largest areas susceptible to deposition are closer to the middle of the cylinder as the velocity increases. The far-field incipient motion and depositional regimes for two similarly hydrodynamic regimes, simulation $3 \mathrm{~b}$ ( $U_{\text {wave }}=25 \mathrm{~cm} / \mathrm{s}$ and $\left.U_{\text {mean }}=10 \mathrm{~cm} / \mathrm{s}\right)$ and simulation $2 \mathrm{c}$ ( $U_{\text {wave }}=10 \mathrm{~cm} / \mathrm{s}$ and $U_{\text {mean }}=25 \mathrm{~cm} / \mathrm{s}$ ), show the sensitivity of the bed stress predictions to the wave-current interactions. Although both simulations are close to the critical limits, simu- 

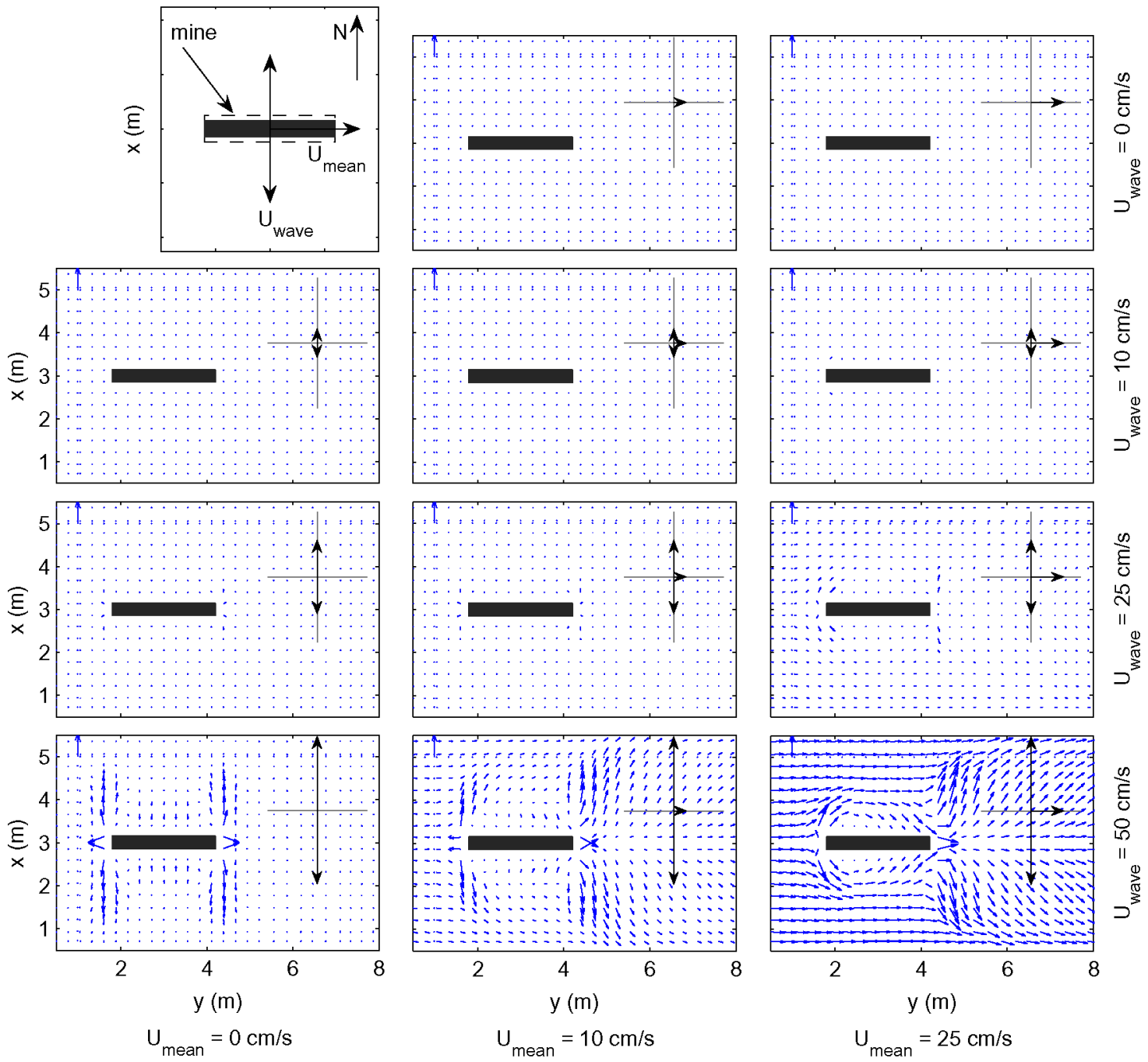

Fig. 6. Bedload transport vectors for wave velocities ranging from 0 (uppermost panels), 10 (upper middle panels), 25 (lower middle panels), and $50 \mathrm{~cm} / \mathrm{s} \mathrm{(lower}$ panels) and mean-flow velocities ranging from 0 (left panels), 10 (middle panels), and $25 \mathrm{~cm} / \mathrm{s}$ (right panels). The vertical arrow in the upper left-hand corner of each panel is the scale vector for representing $6 \times 10^{5} \mathrm{~m}^{2} / \mathrm{s}$. The gray rectangle represents the bed surface area occupied by the cylinder.

lation 3b shows far-field incipient motion (i.e., live-bed scour), while simulation $2 \mathrm{c}$ shows only local incipient motion at the west end of the cylinder (i.e., clear-water scour).

\section{DISCUSSION}

Predicting the sediment initiation and deposition over a flat bed is the first step in predicting the dynamic scour and burial of submerged mines. Comprehensive morphologic simulations require accurate calculations of the transport followed by continuous updates of the morphology. Due to the fixed-bed assumption in this effort, only the initiation of sedimentation is predicted, as evolution of the bed during the events would result in potentially significant variation of the stress and resulting transport and morphologic evolution. Nonetheless, the calculation of the morphologic evolution from a flat bed provides us with an opportunity to evaluate the impact of introducing an object to a previously undisturbed bed. For this effort, the morphologic calculation is simplified by assuming the scour is purely a function of bedload transport. Following [23], we calculate the bedload transport with the model of Engelund and Fredsøe [24] given by

$$
q_{b_{i}}=\frac{1}{6} \pi d_{50}^{3} \frac{P_{E F}}{d_{50}^{2}} U_{b_{i}}
$$

where $U_{b_{i}}=a u_{*_{i}}, a=10, i=x$ or $y$ based on direction, and

$$
P_{E F}=\left[1+\left(\frac{\frac{1}{6} \pi \mu_{d}}{\theta-\theta_{c}}\right)^{4}\right]^{-1 / 4}
$$

where $\mu_{d}=0.51$ and $\theta=|\theta(x, y, t)|$ given by (6), [23].

The model predictions of transport show negligible transport for wave velocities of $10 \mathrm{~cm} / \mathrm{s}$ or less (Fig. 6). When the wave velocity reaches $25 \mathrm{~cm} / \mathrm{s}$, sediment is transported radially away from the cylinder ends. Sediment is also transported downstream when the waves are enhanced by nonzero mean flows. In the presence of the largest wave forcing $\left(U_{\text {wave }}=50 \mathrm{~cm} / \mathrm{s}\right)$, the near-field transport is enhanced by the live-bed transport present in the far-field. 

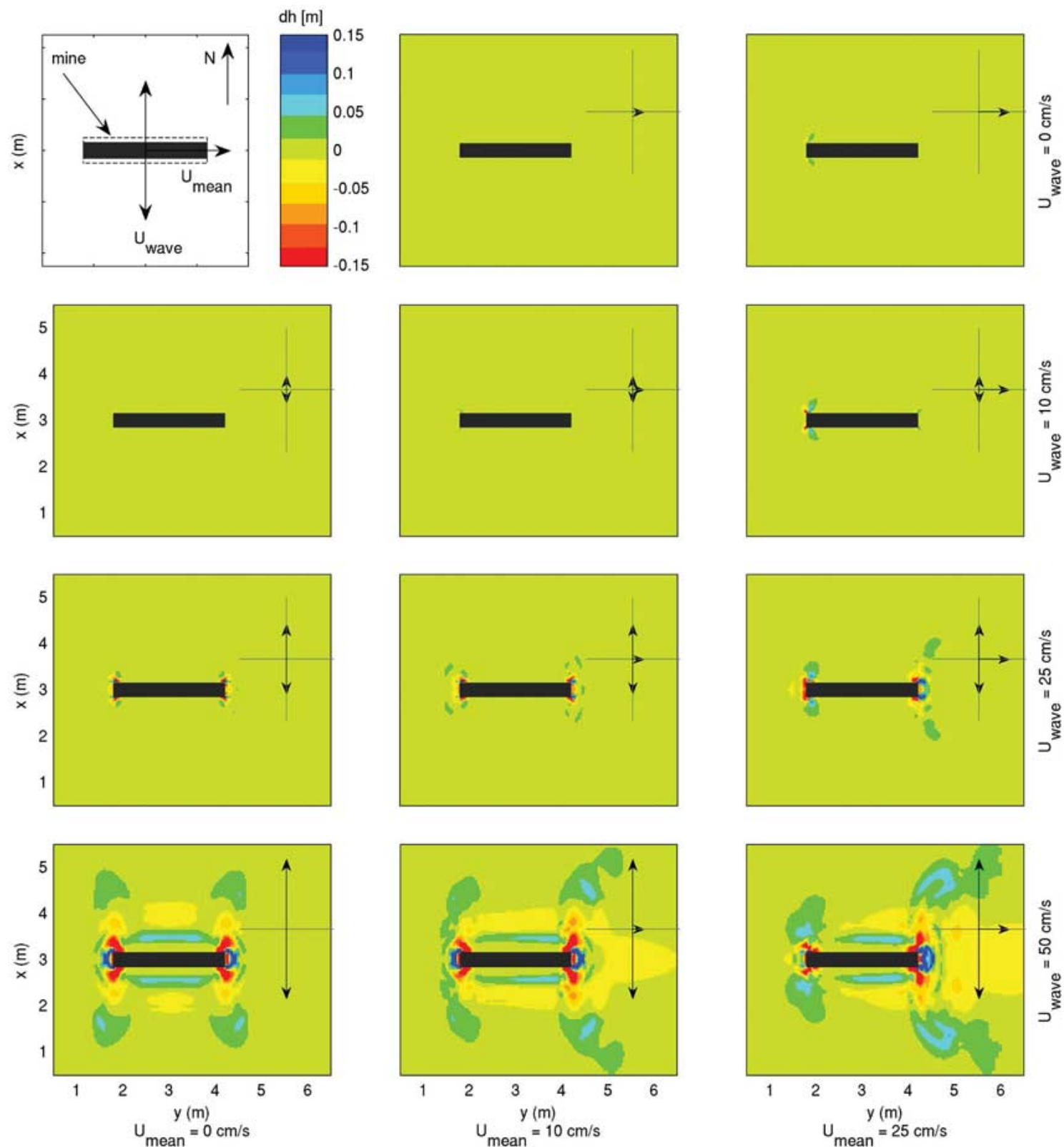

Fig. 7. Color contours of the morphologic change $d h$ for wave velocities ranging from 0 (uppermost panels), 10 (upper middle panels), 25 (lower middle panels), and $50 \mathrm{~cm} / \mathrm{s}$ (lower panels) and mean-flow velocities ranging from 0 (left panels), 10 (middle panels), and $25 \mathrm{~cm} / \mathrm{s}$ (right panels). The gray rectangle represents the bed surface area occupied by the cylinder.

Predictions of bathymetric change may be estimated by integrating the sediment flux over a given amount of time. The predicted scour depth $d h$ is estimated by integrating the Exner equation and is given by

$$
\frac{-d h}{d t}=\frac{1}{1-n}\left[\frac{\partial q_{x_{i}}}{\partial x_{i}}+\frac{\partial V_{s}}{\partial t}\right]
$$

where $V_{s}$ is the volume of sediment in suspension, which is assumed to be 0 .

As an initial approximation, the contributions by the suspended sediment term are assumed negligible. Fig. 7 presents the predicted scour depth for each simulation following $1 \mathrm{~h}$ of exposure to the given forcing conditions. As expected, the simulations show relatively no morphologic evolution for low forcing climates. Whole morphologic evolution in the model is in response to the near-field flow disturbance. In all cases where there is a nonzero transport, scour is predicted at the cylinder ends. The scour resulting from $1 \mathrm{~h}$ of hydrodynamic forcing can reach values of approximately one-half of the mine diameter. The morphologic evolution is larger than would be expected in the field because the flow field does not evolve with the bathymetric changes and suspended load transport is neglected. Predicted scour areas agree well with field observations and previous predictions based on shear stress, with areas of scour occurring near cylinder ends and at areas with high predicted bedload. Areas of deposition are less consistent with field observations and previous results based on the Rouse parameter. These areas are a result of both the flat-bed assumption and the assumption that all sediment stays in bedload. Given higher wave 
and mean forcing conditions the sediment in these areas may be advected downstream or into suspended load, preventing deposition in these areas.

\section{CONCLUSION}

Model simulations of scour and deposition surrounding a partially buried, fixed, cylindrical object exposed to mean flow and wave forcing have been performed for a range of conditions observed in intermediate water depths. The flow simulations are performed for a short cylindrical object assuming a $10 \%$ initial burial on a flat, fixed bed. The cylinder axis is perpendicular to the direction of wave propagation and parallel to mean flow. Regions of scour are identified as locations where the magnitude of the maximum Shields parameter at peak wave velocities is in excess of the limit $\left(\theta_{\text {crit }}=0.06\right)$. Regions of deposition are assumed at locations where the Rouse parameter exceeds ten. Predictions of bedload transport are used to estimate initial morphologic evolution.

In wave-dominated environments, the observations and model predictions show scour occurring at the ends of the cylinder. Both observations and simulations show that for moderate wave forcing in the presence of nonzero mean flows, the scour becomes larger at the upstream end of the cylinder. The fixed-bed assumption in the model simulations prohibits the prediction of complete perimeter scour occurring during the peak storm events. However, predictions of scour surrounding a 2-D pipeline by Smith [22] indicate the likely downstream propagation of scour holes along the length of the cylinder which would eventually result in full perimeter scour surrounding the cylinder. In moderate wave climates ( $U_{\text {wave }}=$ $10 \mathrm{~cm} / \mathrm{s}$ ), the predictions of the Rouse parameter suggest sediment deposition would occur near the center of the cylinder as is regularly observed in the field. However, the bedload transport calculations show no comparable morphologic evolution. This would indicate that sediment deposition over the center of the mine results from suspended load transport. In larger hydrodynamic forcing climates, calculations of the Rouse parameter do not predict strong instances of sediment deposition and are consistent with field observations. However, predictions of bedload transport show larger amounts of deposition not evident in existing observations. These results indicate that the local morphologic evolution surrounding mines is dependent on both bedload and suspended load transport.

Scour and depositional regimes for a complete range of forcing conditions show several trends as velocities increase. The trends allow for more scour and less deposition as velocities increase, with the perpendicular wave velocities dominating the large scale scouring processes and mean-flow velocities dominating the presence of deposition along the length of the cylinder. These regimes may be useful as a resource in determining the local scour and depositional processes surrounding a submerged mine and the effects of changing wave and mean-flow climates on those processes.

\section{REFERENCES}

[1] B. M. Sumer and J. Fredsøe, "Scour around pile in combined waves and current," J. Hydraulic Eng., vol. 127, no. 5, pp. 403-411, May/Jun. 2001.
[2] E. M. Laursen, "An analysis of relief bridge scour," J. Hydraulic Div., vol. 89, no. HY3, pp. 93-118, May 1963.

[3] B. M. Sumer, H. R. Jensen, Y. Mao, and J. Fredsøe, "Effect of lee-wake on scour below pipelines in current," J. Waterway Port Coast. Ocean Eng., vol. 114, no. 5, pp. 599-614, Sep. 1988.

[4] S. P. Kjeldsen, O. Gjørsvik, K. G. Bringaker, and J. Jacobsen, "Local scour near offshore pipelines," in Proc. 2nd Int. Conf. Port Ocean Eng. Arctic Conditions, Reykjavik, Iceland, 1973, pp. 308-331.

[5] Y.-M. Chiew, "Mechanics of local scour around submarine pipelines," J. Hydraulic Eng., vol. 116, no. 4, pp. 515-529, Apr. 1990.

[6] B. M. Sumer and J. Fredsøe, "Onset of scour below a pipeline exposed to waves," in Int. J. Offshore Polar, Sep. 1991, vol. 1, no. 3, pp. 189-194.

[7] B. M. Sumer, N. Christiansen, and J. Fredse, "The horseshoe vortex and vortex shedding around a vertical wall-mounted cylinder exposed to waves," J. Fluid Mech., vol. 332, no. 5, pp. 41-70, Sep./Oct. 1997.

[8] W. Rodi, "Comparison of LES and RANS calculations of the flow around bluff bodies," J. Wind Eng. Ind. Aerodyn., vol. 69-71, pp. $55-75,1997$

[9] R. J. Martinuzzi and M. AbuOmar, "Study of the flow around surface-mounted pyramids," Exp. Fluids, vol. 34, no. 3, pp. 379-389, Mar. 2003.

[10] W. H. Schofield and E. Logan, "Turbulent shear flow over surface mounted obstacles," J. Fluids Eng., vol. 112, no. 4, pp. 376-385, Dec. 1990.

[11] H. J. Hussein and R. J. Martinuzzi, "Energy balance for turbulent flow around a surface mounted cube placed in a channel," Phys. Fluids, vol. 8, no. 3, pp. 764-780, Mar. 1996.

[12] C. Truelsen, B. M. Sumer, and J. Fredsøe, "Scour around spherical bodies and self-burial," J. Waterway Port Coast. Ocean Eng., vol. 131, no. 1, pp. 1-13, Jan. 2005.

[13] H. Shamloo, N. Rajaratnam, and C. Katopodis, "Hydraulics of simple habitat structures," J. Hydraulic Res., vol. 39, no. 4, pp. 351-366, 2001.

[14] F. Y. Testik, S. I. Voropayev, and H. J. S. Fernando, "Flow around a short horizontal bottom cylinder under steady and oscillatory flows," Phys. Fluids, Apr. 2005, in Press.

[15] S. I. Voropayev, F. Y. Testik, H. J. S. Fernando, and D. L. Boyer, "Burial and scour around short cylinder under progressive shoaling waves," Ocean Eng., vol. 30, no. 13, pp. 1647-1667, Sept. 2003.

[16] P. Traykovski, M. D. Richardson, J. A. Goff, L. Mayer, R. Wilkens, and B. Gotowoka, "Mine burial experiments at the Martha's Vineyard Coastal Observatory," in Proc. 6th Int. Symp. Tech. Mine Problems, Monterey, CA, 2004

[17] P. Traykovski, M. D. Richardson, L. A. Mayer, and J. D. Irish, "Mine burial experiments at the Martha's Vineyard Coastal Observatory," IEEE J. Ocean. Eng., vol. 32, no. 1, pp. 150-166, Jan. 2007.

[18] J. E. Richardson and V. G. Panchang, "Three-dimensional simulation of scour-inducing flow at bridge piers," J. Hydraulic Eng., vol. 124, no. 5, pp. 530-540, May 1998.

[19] H. D. Smith and D. L. Foster, "Modeling of flow around a cylinder over a scoured bed," J. Waterway Port Coast. Ocean Eng., vol. 131, no. 1, pp. 14-24, 2005.

[20] D. C. Wilcox, Turbulence Modeling for CFD, 2nd ed. La Canada, CA: DCW Industries, 2000.

[21] P. Y. Julien, Erosion and Sedimentation. Cambridge, U.K.: Cambridge Univ. Press, 1998.

[22] H. D. Smith, "Modelling the flow and scour around an immovable cylinder," M.S. thesis, Civil Environ. Eng. Geodetic Sci. Dept., The Ohio State Univ., Columbus, OH, 2004.

[23] A. Roulund, B. M. Sumer, J. Fredsøe, and J. Michelsen, "Numerical and experimental investigation of flow and scour around a circular pile," J. Fluid Mech., vol. 534, pp. 351-401, 2005.

[24] F. A. Engelund and J. Fredsøe, "A sediment transport model for straight alluvial channels," Nordic Hydrol., vol. 7, no. 5, pp. 293-306, 1976.

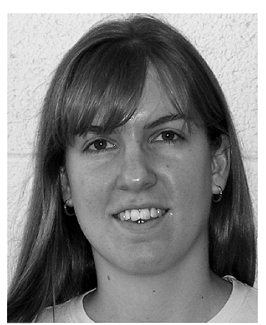

Kimberly A. Hatton received the B.S. and M.S. degrees in civil engineering from the Ohio State University, Columbus, in 2004 and 2006, respectively.

Currently, she is an Engineer at Malcolm Pirnie, Columbus, $\mathrm{OH}$. Her research interests involve small scale sediment transport processes.

Miss Hatton is a member of the American Geophysical Union and the American Society of Civil Engineers. 


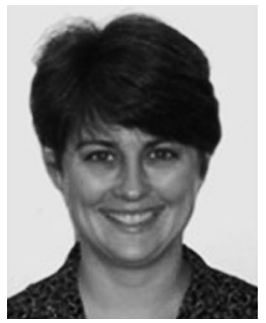

Diane L. Foster received the B.S. degree in mechanical engineering from the University of Massachusetts, Amherst, in 1989, the M.S. degree in mechanical engineering from the University of Maine, Orono, in 1991, and the Ph.D. degree in civil engineering from the Oregon State University, Corvallis, in 1996.

She is an Assistant Professor at the Civil and Environmental Engineering and Geodetic Science Department, Ohio State University. Her research interests include small scale sediment transport, nearshore processes, and the scour and burial of submarine structures.

Dr. Foster is a member of the American Geophysical Union and the American Society of Civil Engineers.

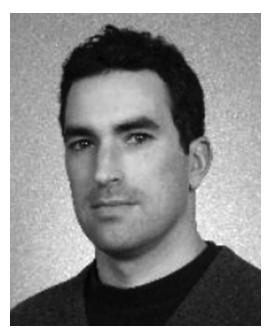

Peter Traykovski received the B.S.E. degree in mechanical engineering from Duke University, Durham, NC, in 1988 and the M.S./Engineers Degree and Ph.D. degree in applied ocean sciences and engineering from the Massachusetts Institute of Technology/Woods Hole Oceanographic Institution Joint Program, Woods Hole, MA, in 1994 and 1998, respectively.

Currently, he is an Associate Scientist at the Applied Ocean Physics and Engineering Department, the Woods Hole Oceanographic Institution. His main research interests are sediment transport dynamics on the continental shelf and in estuaries and developing instrumentation to measure these processes.

Dr. Traykovski is a member of the American Geophysical Union.

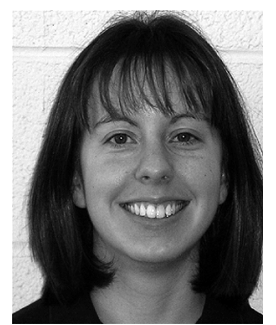

Heather D. Smith received the B.S. and M.S. degrees in civil engineering from the Ohio State University, Columbus, in 2001 and 2004, respectively, where currently, she is working towards the Ph.D. degree.

Her research interests include modeling fuid-structure-sediment interactions, small scale sediment transport, and turbulence.

Miss Smith is a member of the American Geophysical Union and the American Society of Civil Engineers. 